\title{
Altered Dopamine Activity after Recovery from Restricting-Type Anorexia Nervosa
}

Walter H. Kaye, M.D., Guido K.W. Frank, M.D., and Claire McConaha, B.S.N.

When ill, women with eating disorders have disturbances of mood and behavior and alterations of catecholamine activity. It is not known whether these alterations are cause or consequence of pathological eating behaviors. To avoid confounding effects of pathologic eating behavior, we studied women who were recovered ( $>1$ year, normal weight, regular menstrual cycles, no restricting eating pattern, no bingeing or purging) from anorexia nervosa $(A N)$ and bulimia nervosa (BN) compared to healthy control women. Recovered AN women had significantly lower height-adjusted weight than did recovered $B N$ women. CSF HVA ( pmol/ml $\pm S D)$, a major metabolite of dopamine, was significantly lower $(p<.02)$ in six restricting-type AN women (131 \pm 49 ) compared to $19 \mathrm{BN}$ women $(216 \pm 73)$ and at a trend $(p<.08)$ less than 13 bulimic-type AN women $(209 \pm 53, p<.06)$ and 18 control women $(202 \pm 57, p<.08)$. These four groups had similar values for CSF MHPG, a norepinephrine metabolite. Dopamine neuronal function has been associated with motor activity, reward, and novelty seeking. These behaviors are altered in restricting-type AN compared to other eating disorder subtypes. A trait-related disturbance of dopamine metabolism may contribute to a vulnerability to develop this sub-type of eating disorder.

[Neuropsychopharmacology 21:503-506, 1999] (C) 1999 American College of Neuropsychopharmacology. Published by Elsevier Science Inc.
KEY WORDS: HVA; CSF; MHPG; Anorexia nervosa; Long term recovery; Eating disorders

Anorexia nervosa (AN) and bulimia nervosa (BN) are disorders of unknown etiology (American Psychiatric Association 1994). The most distinguishing characteristic of AN is severe emaciation. Two subtypes have been identified: Restricting-type AN patients lose weight by pure dieting; Bulimic anorexics also restrict food, but engage episodically in inappropriate compensatory behaviors. BN subjects remain at normal weight and repeatedly binge and purge or engage in other compensatory behaviors.

Animal and human studies (Morley and Blundell

From the Department of Psychiatry, Western Psychiatric Institute and Clinic, University of Pittsburgh School of Medicine, Pittsburgh, PA

Address correspondence to: Walter H. Kaye, M.D., Western Psychiatric Institute and Clinic, 3811 O'Hara Street E-24, Pittsburgh, PA 15213.

Received September 28, 1998; revised February 4, 1999; accepted April 9, 1999.
1988) suggest that altered central nervous system catecholamine neurotransmitter activity could contribute to appetitive, neuroendocrine, and behavioral disturbances in individuals with eating disorders (EDs). In fact, altered catecholamine activity has been found among ill $\mathrm{AN}$ and $\mathrm{BN}$ individuals. Homovanillic acid (HVA), the major metabolite of dopamine (DA) in humans (Amin et al. 1992), was decreased in cerebrospinal fluid (CSF) of underweight AN subjects (Kaye et al. 1984). While ill BN subjects, as a group, have normal CSF HVA, several studies have shown a significant reduction of CSF HVA in $\mathrm{BN}$ patients with high binge frequency (Kaye et al. 1990; Jimerson et al. 1992). Most studies have found abnormalities of peripheral and central noradrenergic activity (Pirke 1996) in ill AN and BN patients.

There are few studies, however, of catecholamine function in people with EDs after recovery. The purpose of this study was to determine whether CSF catecholamine concentrations normalize after long-term recovery from $\mathrm{AN}$ and $\mathrm{BN}$. 


\section{METHODS}

Thirty-eight long term recovered women were recruited who previously had met DSM-IV criteria for an ED: 19 subjects recovered from AN: six restricting-type AN subjects (rAN-R) and 13 bulimic AN subjects (rAN-B/P); and 19 subjects recovered from normal weight $B N$ (rNWB). The Eating Disorders Family History Interview (M Strober unpublished manuscript, 1987) and past records were used to establish a diagnosis of an eating disorder. The rAN-R subjects had never had BN, the rNWB subjects had never had AN. In the year before the study, participating subjects had to maintain a body weight of greater than $90 \%$ average body weight (\% ABW) (Metropolitan Life Insurance Company 1959); have regular menstrual cycles; not binge, purge, or restrict food intake; and not meet criteria for substance abuse or dependence. Relatively normal dietary intake (daily caloric intake of $>20 \mathrm{kcal} / \mathrm{kg}$ ) and meal patterns was confirmed during the clinical interview. Due to the difficulty of finding recovered AN subjects, we included four subjects below $90 \%$ ABW (two rAN-R who were $85 \%$ and $89 \%$; and two rAN-B/P who were $88 \%$ and $89 \%$ ). Subjects must not have used psychoactive medication within 30 days of the study. Subjects recovered from an eating disorder were compared to 18 healthy control women (NC), who were matched most closely to the rNWB and who had no lifetime history of psychiatric or chronic medical illnesses. Clinical descriptions of the recovered subjects and controls have been described elsewhere (see Srinivasagam et al. 1995; Kaye et al. 1998). After given a complete description of the study, all subject's written informed consent was obtained.

A lumbar puncture (LP) was done during the first ten days of the follicular phase of the subjects menstrual cycle. Subjects were admitted one day prior to the LP to the research laboratory of the Western Psychiatric Institute and Clinic. They were served a standardized, monoamine controlled diet during their stay. Before the $\mathrm{LP}$, the subjects fasted from midnight until the procedure was done, between 8 A.M. and 10 A.M. the next morning. The LP was done with subjects in left lateral position in the L 3/4 intervertebral space. Samples were preserved in ascorbic acid, immediately frozen and stored at $-70^{\circ} \mathrm{C}$. At the time of the $\mathrm{LP}$, blood was drawn for assessment of beta-hydroxy butyrate ( $\beta \mathrm{HBA})$, a plasma ketone body that is relatively sensitive in reflecting the presence of starvation (Fichter et al. 1990).

All assays were done by laboratory staff blind to the clinical data. High-performance liquid chromatography (Scheinin et al. 1983) was used to assay the major CSF dopamine metabolite (HVA), and the norepinephrine metabolite 3-methoxy-4-hydroxyphenylglycol (MHPG). The within-run and between-run CV of each catecholamine assay was less than $10 \%$. $\beta$ HBA was measured us- ing the enzymatic method of Williamson (Williamson et al. 1962) (CV of $4 \%$ ).

The BMDP Statistical Software package was used for data analysis (Dixon 1985). Correlation coefficients were calculated for all groups together as Spearman Correlation Coefficients (SpCC). Significant correlations were taken into consideration as covariates. Analysis of covariance (ANCOVA) and Tukey post-hoc tests examined inter-group differences. Data are expressed as means \pm standard deviation (SD).

\section{RESULTS}

The CW and ED subgroups had similar ages at the time of study (Table 1). The rAN-R, rAN-B/P, and CW subjects had similar current weight. However, the two AN subgroups weighed less than the rNWB. As expected lifetime high and low body weights differed between subgroups. Plasma $\beta$ HBA was similar between groups.

An ANOVA revealed a significant group difference $(d f=3,52 ; \mathrm{F}=2.06 ; p=.04)$ for CSF HVA (Table 1, Figure 1). Post-hoc testing showed that CSF HVA in rAN-R was significantly reduced $(p<.05)$ compared to the rNWB and at a trend $(p<.1)$ less than the $\mathrm{rAN}-\mathrm{B} / \mathrm{P}$ or NC women. CSF MHPG was similar between groups. When the ED subjects were compared without the CW, CSF HVA was significantly reduced in rAN-R subjects compared to $\mathrm{rAN}-\mathrm{B} / \mathrm{P}$ or the rNWB group. When the ED groups were considered together, CSF HVA values were negatively related to $\beta \mathrm{HBA}(p<.05 ; \mathrm{SpCC}=0.36$; and $n=30$ ). CSF HVA concentrations in rAN-R remained significantly reduced ( $\mathrm{rAN}-\mathrm{R}$ vs. $\mathrm{rNWB}$ : $\mathrm{F}=$ $6.3, p<.01$; rAN-R vs. rAN-B/P: $\mathrm{F}=5.4, p<.05)$ after $\beta H B A$ was covaried with HVA.

\section{DISCUSSION}

These data raise the possibility that a disturbance of DA metabolism persists after recovery from restricting-type AN. Previously, only a few other studies have reported catecholamine activity after recovery from EDs. We previously reported (Kaye et al. 1984, 1991) that a small number of recovered AN subjects had normal CSF HVA and MHPG levels. Diagnostic subdivisions were done by chart reviews in many cases instead of by a direct interview because when these earlier studies were done, it was not well recognized that there were subgroups of AN subjects. Still, these earlier data hint at low HVA in rAN subjects since three of the 5 five were among the lowest in terms of HVA values. In addition, our group reported normal CSF HVA and MHPG levels in rNWB subjects who never had AN (Kaye et al. 1998).

Is reduced CSF HVA in restricting-type AN due to dif- 
Table 1. Comparison of subjects with subtypes of eating disorders (Mean \pm SD)

\begin{tabular}{|c|c|c|c|c|c|c|}
\hline & $\begin{array}{l}\text { Recovered } \\
\text { restricting-type } \\
\text { anorexics } \\
\text { (rAN-R) }\end{array}$ & $\begin{array}{c}\text { Recovered } \\
\text { anorexics-binge } \\
\text { eating/purging type } \\
(\mathrm{rAN}-\mathrm{B} / \mathrm{P})\end{array}$ & $\begin{array}{c}\text { Recovered } \\
\text { normal weight } \\
\text { bulimics } \\
\text { (rNWB) }\end{array}$ & $\begin{array}{l}\text { Control } \\
\text { women } \\
(\mathrm{CW})\end{array}$ & $F$ & $p$ \\
\hline$n$ & 6 & 13 & 19 & 18 & & \\
\hline Age (years) & $21.5 \pm 2.5$ & $25.1 \pm 3.2$ & $26.8 \pm 6.3$ & $23.2 \pm 4.3$ & 2.7 & .053 \\
\hline Current \% ABW & $96 \pm 7^{a}$ & $98.1 \pm 10^{b}$ & $110 \pm 9^{a, b}$ & $106 \pm 8$ & 6.8 & .001 \\
\hline$\%$ ABW (high lifetime adult weight) & $99 \pm 6^{a}$ & $113 \pm 20$ & $125 \pm 15^{a, b}$ & $110 \pm 8^{b}$ & 6.5 & .001 \\
\hline$\%$ ABW (low lifetime adult weight) & $69 \pm 8^{a, c}$ & $69 \pm 8^{b, d}$ & $94 \pm 8^{a, b}$ & $96 \pm 8^{c, d}$ & 44.1 & .000 \\
\hline Age of onset of eating disorder (years) & $14.4 \pm 1.6$ & $14.3 \pm 2.3$ & $16.2 \pm 3.5$ & - & 1.9 & .17 \\
\hline Length of recovery (months) & $45.0 \pm 30.7$ & $31.7 \pm 19.5$ & $40.3 \pm 25.4$ & - & 0.8 & .47 \\
\hline$\beta \mathrm{HBA}(\mu \mathrm{mol} / \mathrm{ml})$ & $114 \pm 17$ & $229 \pm 163$ & $128 \pm 164$ & $119 \pm 89$ & 1.3 & .28 \\
\hline $\mathrm{HVA}(\mathrm{pmol} / \mathrm{ml})$ & $131 \pm 49^{a}$ & $209 \pm 53$ & $216 \pm 73^{a}$ & $202 \pm 57$ & 3.1 & .04 \\
\hline $\mathrm{MHPG}(\mathrm{pmol} / \mathrm{ml})$ & $40 \pm 13$ & $48 \pm 27$ & $38 \pm 14$ & $42 \pm 13$ & 0.8 & .47 \\
\hline
\end{tabular}

$\mathrm{df}=3$ for all comparisons, except for age of onset of $\mathrm{ED}$, and length of recovery $(\mathrm{df}=2)$; values with identical superscript in the same row (i.e., a vs. a) are significantly different $(p<.05$; Tukey's post hoc test); abbreviations: ABW (average body weight), $\beta$ HBA (beta-hydroxy butyrate), HVA (homovanillic acid), MHPG (3-methoxy-4-hydroxyphenylglycol).

${ }^{a}$ Values with identical superscripts in the same row (i.e., a vs. a) are significantly different.

${ }^{b}$ Same as above.

${ }^{c}$ Same as above.

${ }^{d}$ Same as above.

ferences in age or weight between subgroups? This is unlikely since these factors were similar for $\mathrm{rAN}-\mathrm{R}$ and rAN-B/P. To avoid the confounding effects of malnutrition we assessed the subjects after recovery from their ED. We found a negative relationship between CSF HVA and plasma $\beta \mathrm{HBA}$, a ketone body which is an index of starvation that is known to be increased in malnourished ED patients (Pahl et al. 1985, Fichter et al. 1990). However, plasma levels of $\beta$ HBA were highest in the $\mathrm{rAN}-\mathrm{B} / \mathrm{P}$, not

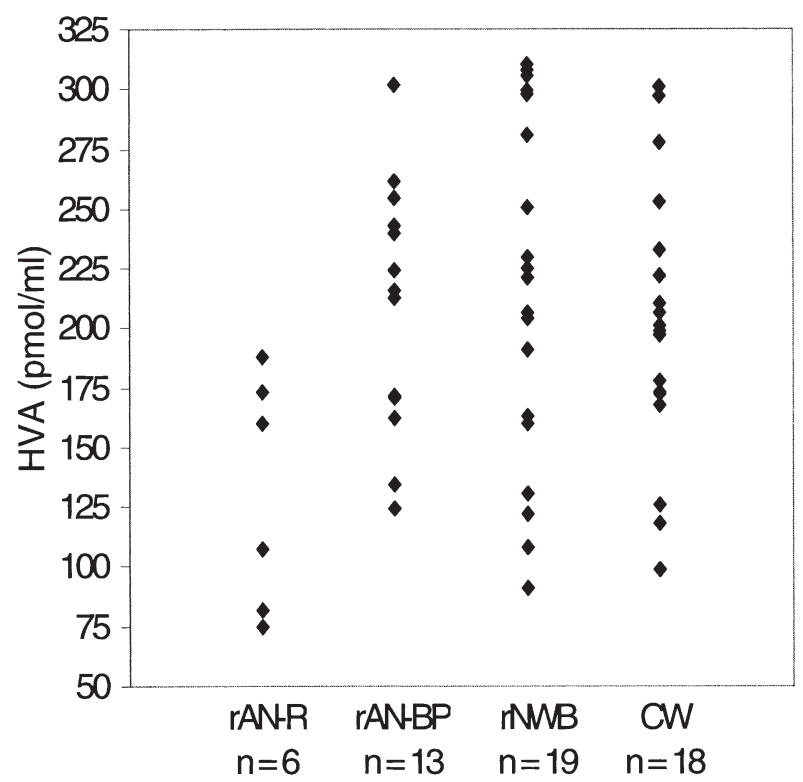

Figure 1. Comparison of significant $(p \leqslant .02)$ differences in CSF HVA concentrations between subgroups of women who have recovered from an eating disorder. the rAN-R, subjects. Thus, persistent food restriction did not account for the reduced HVA in rAN-R subjects.

Since the number of subjects studied was small, this finding will need to be replicated in larger a subgroup. The relevance of CSF monoamine measurements is often questioned despite a literature showing CSF HVA reflects the pathophysiology of Parkinson Disease (Olsson and Roos 1968; Mena et al. 1984). Thus, it may be useful to utilize newer technologies, such as PET imaging with dopamine ligands.

Recent studies suggest a shared etiologic vulnerability for AN and BN (Walters and Kendler 1995; Kendler et al. 1991). In support of this possibility, recovered AN and $\mathrm{BN}$ patients demonstrate similar persistent behavioral symptoms, such as obsessive perfectionism and exactness, and negative affect (Kaye et al. 1998; Srinivasagam et al. 1995). Other vulnerabilities may be necessary to develop a subtype, such as restricting-type AN. Brain DA systems play a role in systems that may be specifically disturbed in restricting-type AN compared to other ED subtypes. For example, individuals with restricting-type AN have stereotyped and hyperactive motor behavior (Kron et al. 1978; Beumont et al. 1994). DA plays a role in locomotor activity and displays of stereotypy in animal studies (Kalivas 1993; Angulo and McEwen 1994). AN individuals have anhedonic, restrictive personalities. They seem to find little in life rewarding aside from losing weight. DA may contribute to motivation and reward (Salamone 1996; Blum et al. 1995). Finally, restricting-type AN individuals have reduced novelty seeking (Sohlberg and Strober 1994), a construct associated with DA metabolism (Bardo et al. 1996). In summary, this preliminary find- 
ing of reduced CSF HVA of rAN-R subjects raises the possibility that altered DA metabolism contributes to restricting-type AN behaviors.

\section{ACKNOWLEDGMENTS}

We would like to thank John Mann, M.D., for performing the catecholamine assays and Penny Crossan for her editorial assistance. This study was supported in part by NIMH R01 MH 42984-04 "The Neurobiology of Feeding Behavior in Bulimia" and R01 MH46001-03 "Serotonin-A Trait Disturbance in Anorexia Nervosa?" and Children's Hospital Clinical Research Center, Pittsburgh PA (\#5M01RR00084).

\section{REFERENCES}

American Psychiatric Association (1994): Diagnostic and Statistical Manual of Mental Disorders. 4th ed. Washington, DC, American Psychiatric Association

Amin F, Davidson M, Davis KL (1992): Homovanillic acid measurement in clinical research: A review of methodology. Schizophr Bull 18(1):123-148

Angulo JA, Mc Ewen BS (1994): Molecular aspects of neuropeptide regulation and function in the corpus striatum and nucleus accumbens. Brain Res Rev 19:1-28

Bardo MT, Donohew RL, Harrington NG (1996): Psychobiology of novelty seeking behavior. Behav Brain Res 77:23-43

Beumont PJV, Arthur B, Russel JD, Touyz S (1994): Excessive physical activity in dieting disorder patients: Proposal for a supervised exercise program. Int J Eat Disord 15(1):21-36

Blum K, Sheridan PJ, Wood RC, Braverman ER, Chen TJ, Comings DE (1995): Dopamine D2 receptor gene variants: Association and linkage studies in impulsive addictive-compulsive behavior. Pharmacogenetics 5(3): 121-141

Dixon J (1985): BMDP Statistical Software. Berkeley, University of California Press

Fichter MM, Pirke KM, Poellinger J, Wolfram G, Brunner (1990):Disturbances in the hypothalamo-pituitary-adrenal and other neuroendocrine axes in bulimia. Biol Psychiatry 27:1021-1037

Jimerson DC, Lesem MD, Kaye WH, Brewerton TD (1992): Low serotonin and dopamine metabolite concentrations in cerebrospinal fluid from bulimic patients with frequent binge episodes. Arch Gen Psychiatry 49:132-138

Kalivas PW (1993): Neurotransmitter regulation of dopamine neurons in the ventral tegmental area. Brain Res Rev 18:75-113

Kaye WH, Ballenger JC, Lydiard RB, Stuart GW, Laraia MT, O’Neil P, Fossey MD, Stevens V, Lesser S, Hsu G (1990): CSF monoamine levels in normal weight bulimia: Evidence for altered noradrenergic activity. Am J Psychiatry 147: 225-229

Kaye WH, Ebert MH, Raleigh M, Lake R (1984): Abnormali- ties in CNS monoamine metabolism in anorexia nervosa. Arch Gen Psych 41:350-355

Kaye WH, Gwirtsman HE, George DT, Ebert MH (1991): Altered serotonin activity in anorexia nervosa after long-term weight restoration. Arch Gen Psychiatry 48:556-562

Kaye WH, Greeno CG, Moss H, Fernstrom J, Fernstrom M, Lilenfeld LR, Weltzin TE, Mann JJ (1998): Alterations in serotonin activity and psychiatric symptomatology after recovery from bulimia nervosa. Arch Gen Psychiatry 55:927-935

Kendler SK, MacLean C, Neale M, Kessler R, Heath A, Eaves L (1991): The genetic epidemiology of bulimia nervosa. Am J Psychiatry 148(12):1627-1637

Kron L, Katz JL, Gorzynski G, Weiner H (1978): Hyperactivity in anorexia nervosa: A fundamental clinical feature. Comprehen Psychiatry 19(5):433-440

Mena MA, Aguado EG, de Jebenes JG (1984): Monoamine metabolites in human cerebrospinal fluid. HPLC/ED method. Acta Neurol Scand 69(4):218-225

Metropolitan Life Insurance Company (1959): New weight standards for men and women. Stat Bull Metrop Insur Co 40:1-11

Morley JE, Blundell JE (1988): The neurobiological basis of eating disorders: Some formulations. Biol Psychiatry 23:53-78

Olsson R, Roos BE (1968): Concentrations of 5-hydroxyindolacetic acid and homovanillic acid in the cerebrospinal fluid after treatment with probenecid in patients with Parkinson's Disease. Nature 219:502-503

Pahl J, Pirke KM, Schweiger U, Warnhoff M, Gerlinghoff M, Brinkmann W, Berger M, Krieg C (1985): Anorectic behavior, mood, and metabolic and endocrine adaption to starvation in anorexia nervosa during inpatient treatment. Biol Psychiatry 20:874-887

Pirke KM (1996): Central and peripheral noradrenalin regulation in eating disorders. Psychiatry Res 62:43-49

Salamone JD (1996): The behavioral neurochemistry of motivation: methodological and conceptual issues in studies of the dynamic activity of nucleus accumbens dopamine. J Neurosci Meth 64:137-49

Scheinin M, Chang WH, Kirk KL, Linnoila M (1983): Simultaneous determination of 3-methoxy-4-hydroxyphenylglycol, 5-hydroxyindoleacetic acid, and homovanillic acid in cerebrospinal fluid with high-performance liquid chromatography using electrochemical detection. Analyt Biochem 131:246-253

Sohlberg S, Strober M (1994): Personality in anorexia nervosa: An update and a theoretical integration. Acta Psychiatry Scand 89(suppl 378):1-15

Srinivasagam NM, Kaye WH, Plotnicov KH, Greeno CG, Weltzin TE, Rao R (1995): Persistent perfectionism, symmetry, and exactness after long term recovery from anorexia nervosa. Am J Psychiatry 152(11):1630-1634

Walters EE, Kendler KS (1995): Anorexia nervosa and anorexic like symptoms in an population based female twin sample. Am J Psychiatry 152:64-71

Williamson DH, Mellanby J, Krebs HA (1962): Enzymatic determination of $\mathrm{D}(-)$ beta hydroxybutyric acid and acetoacetic acid in blood. Biochem J 82:90-96 